\title{
The Frequency of Expressions and Proverbs in Different Iranian Generations' Speech Styles
}

\author{
Mohammad Saber Khaghaninejad $^{1 *}$, Saharsaadat Hadigheh ${ }^{2}$ \\ ${ }^{1}$ Department of Foreign Languages and Linguistics, Shiraz University, Shiraz, Iran \\ 2Shiraz University of Medical Sciences, Paramedical Faculty of Gerash, Iran \\ *E-mail address: mskhaghani@shirazu.ac.ir, Hadighes@sums.ac.ir
}

\begin{abstract}
Change is one of the fundamentals of every language. Every community consists of different generations with various perspectives toward life. The difference among different generations' vernaculars are so drastic that it would not be an exaggeration to claim that every generation of a society or a speech community has its own language or vernacular which distinguishes it from other generations or age-groups of the society in lexico-grammatical terms. This study put the frequency of expressions and proverbs in different generations' speech styles under investigation. Hence, inspired by stratified randomization technique, the researcher randomly selected a group of 24 middle-aged and similarly a group of 24 teenager participants of the two genders. Each of the age-groups consisted of 12 male and 12 female subjects in order to provide the possibility to determine the role of gender on expression or proverb usage. All the subjects were individually interviewed for elicitation of the needed data then their sentences were recorded and accurately transcribed for further investigation. By counting the expressions or proverbs in sentences of male/female teenagers' and middle-aged subjects of the research, their expression and proverb usage frequencies were illuminated. The study's results suggested that middle-aged speakers of Iranian community employed expressions and proverbs more than teenagers. This implies that the older would have a stronger relationship with the literature and are more satisfied with their culture and identity. Middle-aged subjects used those expressions which were deeply rooted in the literature and culture while teenagers were highly in use of those expressions and proverbs which were suddenly entered into the lexicon of the society by the advent of new television series or expanded advertisements of mass media, for example. Furthermore, it was found that males generally were more interested in using expression and proverb in their daily conversations than females.
\end{abstract}

Keywords: Vernaculars; Speech community; Stratified randomization; Lexical density; Expression density (ED)

\section{INTRODUCTION}

The specialized vernacular of each generation is highly influenced by socio-economic factors. Petyt (1980) defined vernacular as 'a form of speech transmitted from parent to child as a primary medium of communication'. Cultural environment, religious beliefs, social welfare, educational background, and the extent to which parents have authority to control their children behaviours can also plays an important role in every generation vernacular 
determination. The researcher personally believes that the vernacular spoken by teenagers today has drastically changed in comparison with the one their peers' spoke 30-40 ago. This change is mostly occurred in the domain of vocabulary usage, in particular, the frequency of expressions and/ or proverbs in daily conversations.

Expressions and proverbs are rooted in culture, beliefs, and literature of a community. Usually expression or proverb usage shows a rich literary background on the speaker's part and a high degree of penetration and acceptance on the listener's. Investigating the patterns of change in expression or proverb usage would provide us with invaluable insights on the quality of cultural change among different generations of the society. Drastic cultural change over few generations may jeopardize the identity of a country. This research tries to figure out the existence of such a change in our own country, which claims to have one of the richest cultures and literatures among other world's countries.

Various sociolinguistic studies presented different definitions for different technical terms independent of other researches of the field. This study's key terms are defined operationally as follows:

- Proverb is a short well-known saying that states a general truth or gives advice.

- Expression is a phrase whose meaning is not clear from the meaning of its individual words.

- Middle-aged subjects are those participants who are between 45 and 60 while Teenager subjects are those participants who are between 13 and 19.

- Stratified randomisation is a technique of randomisation in which the composition of the needed sample of study is pre-determined. The participants of each category are randomly selected based on certain specifications like, age or sex until the desired quota is reached. These definitions are not new and mentioned just for the sake of certainty and clarification.

As previously mentioned, this study tried to provide reasonable answers to the following questions:

- Is there any difference between teenagers and middle-aged speakers of Iranian community in terms of expression or proverb usage in daily conversations?

- Is there any difference between male and female speakers of each group (teenager and middle-aged) while the frequency of expressions and proverbs in daily conversation is concerned?

\section{LITERATURE REVIEW}

Age is among those socio-economic factors which accompanying sex and social class, cause variation in language. Different age groups use different structural patterns or vocabularies. In fact, difference in language is one of the way in which different age groups are distinguished from one another.

Labov (1973) scrutinized age as a factor of sociolinguistic variation in Japan. He investigated the Japanese "high-school girl" talk and reached to interesting patterns of speech variation compared to speech style the older workers of the neighbouring factory. He also claimed that the concept of language attrition is just related to the older speakers of the community who speak a more conservative, fixed language than other speakers of the society.

The age-graded phenomenon, whereby young children speak differently from older children and, in turn, children speak differently from mature adults and (in general every age- 
group has its particular style of speaking) is another evidence for age-relevant linguistic behaviour which was introduced in 1980s.

Macaulay's study (1977) investigated the element of age in linguistic behaviour in different age-groups in Glasgow. He concentrated in vowel pronunciation of different generations. Macaulay surveyed sixteen adults, sixteen 15-year-olds, and sixteen 10-yearolds, with equal numbers of males and females represented in each group. He found that increase in age seemed to be associated with an increase in lengthened pronunciation of vowels. He also concluded that adults speak a more comprehensible language that 15-yearolds or 10-year-olds.

In another age related study by Labov in 1973, it was determined that the languages of those whose ages are between 31 and 45 are subject to numerous changes. Labov, as the conclusion of his study mentioned that 'the very olds follow older ways, which do not involve as much centralization. But one between 31 and 45 is likely to employ those fashion terms which are entered into the lexicon of the society most recently'.

That there are differences between the sexes is hardly a matter of dispute. The female voice usually has different characteristics from the male voice, and often females and males exhibit different ranges of verbal skills.

Numerous observers had described women's speech as being different from that of men (e.g., Labov, 1973; Herbert, 1990). In the linguistic literature perhaps the most famous example of linguistic differentiation between sexes is said to occur in the Lesser Antilles of the West Indies among the Carib Indians. Males and female Caribs are said to speak different languages, the result of a long-ago conquest in which a group of invading Carib-speaking men killed the local Arawak-speaking men and mated with the Arawak women. The descendents of these Carib-speaking men and Arawak-speaking women are sometimes described as having different languages for men and women. The differences actually do not result in two separate or different languages, but rather one language with noticeable sex-based characteristics (Taylor, 1951).

Phonological differences between the speech of men and women have been noted in variety of languages. In Gros Ventre, an Amerindian language of the northeast United States, women have palatalised velar stops where men have palatalised dental stops. It is interesting that when a female speaker of Cros Ventre quotes a male, she attributes female pronunciation to him, and when a male quotes a female, he attributes male pronunciation to her. Moreover, any use of female pronunciation by males is likely to be regarded as a sign of effeminacy.

In the area of morphology and vocabulary, many of the studies have focused on English. Lakoff (1973), for example, claimed that women use colour words like mauve, beige, aquamarine, lavender, and magenta but most men do not. She also maintains that adjectives such as adorable, charming, divine, lovely, and sweet are also commonly used by women but only very rarely by men. Women are also said to have their own vocabulary for emphasizing certain effects on them, words and expressions such as so good, such fun, exquisite, lovely, precious, darling, and fantastic.

Haas (1964), conducted a research in south-western Louisiana where Koasati, an Amerindian language is spoken on sex-based linguistic variation and concluded that men and women language differ in vocabulary choice, intonation patterns, tag questions, and paralinguistic systems. He added that 'different languages do seem to prescribe different forms for use by men and women'.

Wardhaugh (1986) claimed that men and women also speak on different topics with men holding forth on such topics as business, politics, legal matters, taxes and sports, and women on social life, books, food and drink, life troubles, and life style. He also drew some 
conclusions about the quality of men and women speech; women speak less forcefully than men and men swear much more than women, men are also blunter and to the point in their speech.

In conversations involving members of both sexes most researchers agree that men speak more than women do. Herbert (1990) also found that when men talked to men, the content categories of such talk focused on competition and teasing, sports, aggression, and doing things. One the other hand, when women talked to women, the equivalent categories were the self, feelings, affiliation with others, home, and family. When the two sexes interacted, men tended to take the initiative in conversation, but there seemed to be a desire to achieve some kind of accommodation so far as topics were concerned.

According to Gumperz (1982) women try to use a different language in social interactions why, they accepted their inferior role in the society and this is a symptom of a problem in our culture. He continues, the greater differences in linguistic behaviour appear to exist in societies in which the roles of men and women are most clearly differentiated.

Herbert (1990) investigated sex-based differences in compliments behaviour. He defined compliment as a two-unit speech event in which utterance 1 and utterance 2 are linked by both temporal and relevancy condition. Herbert claimed that compliments display a surprisingly limited range of syntactic patterns, which show interesting facts about sex-based linguistic variation. He concluded that women try to employ more personal focus in their compliments, which are mostly about appearance or new possessions, while men-offered compliments are impersonal expressions, which are mostly about gaining a new skill or position. He also concluded that female compliments are longer, subjective and containing a higher degree of hedges while male compliments are shorter and objective and full of certainty. He also mentioned that females use compliments in order to offer solidarity while males use compliments mostly for showing their praise or acceptance.

\section{METHOD}

\subsection{Subjects}

The researchers tried to investigate the frequency of expressions and proverbs in daily conversations of two different generations. In this regard inspired by stratified randomisation technique, they randomly selected a group of 24 middle-aged (45-60) and a group of 24 teenager participants of both genders. Each age-group consisted of 12 male and 12 female subjects for providing the possibility of determining the role of gender in expression or proverb usage. The researchers also tried to equate the two sub-groups of each age-group in terms of education and social class. So, based on the factors of age, sex, education and social class, the researcher selected appropriate subjects for the study.

\subsection{Procedure}

In order to determine the frequency of expressions and proverbs in daily conversations of two different generations, the researchers had to find a way in which the participants speak as freely as possible. In fact, he had to try to minimize the effect of observer's paradox on the participants. Otherwise, they would have avoided using expressions in their speech. Considering some ethical principles of sociolinguistic studies, the researcher made them aware of being the subjects of a study but they were not explained about where the focus of 
the study is put. They were asked to narrate one memory or one interesting event of their lives while their sentences were recorded. In order to reduce the effect of Labov's observer's paradox, the subjects were told that the researcher would polish their sentences and were asked to talk in the way they usually talk.

\subsection{Data collection}

Among all elicitation techniques of gathering data, individual interview seemed most logical and applicable. Although interview is one of the most demanding of elicitation techniques, the researcher tried to observe all proposed guidelines of conducting an interview by Fasold (1972), for example, showing interest and enthusiasm on what the interviewee is relating or attempting to alleviate informant's consciousness of his speech.

The context of interview is also a vital factor which can increase or decrease the informant's stress or anxiety. A well-selected atmosphere of interview can minimize the effect of observer's paradox. Participants of this study were all interviewed in context to which they had a sense of membership, for example, middle-aged participants were interviewed while they saw their peers or friends nearby on a park bench or their workplaces and teenagers were asked to talk mostly in the faculty's cafeteria or their own rooms in dormitory.

Their sentences were recorded for further investigation by their own permission and then accurately transcribed. Then, numerating expressions and proverbs in the speech of male/female teenagers and middle-aged subjects of the research, made it possible to survey the frequency of expressions and proverbs among the participants of each age-group and subgroup separately. In this way, the considered area of interest had been illuminated and some reasonable answers had been found for the research questions.

\section{DATA ANALYSIS}

\subsection{Expression density}

In order to study the frequency of expressions and proverbs in daily conversations of two distinct generations, inspired by the notion of lexical density, the researcher defined an equivalent notion; expression density (ED) which shows the number of expressions per each individual clause.

\section{The number of expression

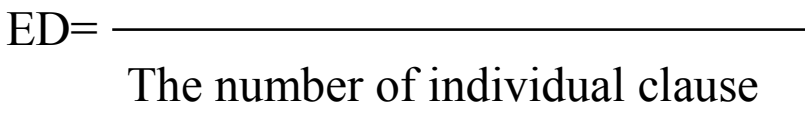

It seems necessary to note that the researcher tried his best to equate the number of participants' clauses of each group in order to make the result of the above mentioned estimation reliable and meaningful. In order to compare the frequency of expressions and proverbs in two different generation speeches, the ED of each generation has been calculated as follows: 


$$
\begin{gathered}
\text { Older generation }=\frac{\mathrm{N} \text { expressions }}{\mathrm{N} \text { clauses }}=\frac{63}{258}=0.24 \\
\text { Younger generation }=\frac{\mathrm{N} \text { expressions }}{\mathrm{N} \text { clauses }}=\frac{31}{139}=0.17
\end{gathered}
$$

The results showed that the older generation uses expressions and proverbs more than the younger one. Of course, the difference is not so drastic. In order to have a comparison between two genders (male and female) on the frequency of expressions and proverbs in daily conversations, the ED of each gender would be estimated as follows. It seems males drastically use more expressions or proverbs than females do.

$$
\begin{aligned}
& \text { Males }=\frac{\mathrm{N} \text { expressions }}{\mathrm{N} \text { clauses }}=\frac{62}{188}=0.33 \\
& \text { Females }=\frac{\mathrm{N} \text { expressions }}{\mathrm{N} \text { clauses }}=\frac{27}{186}=0.13
\end{aligned}
$$

\section{CONCLUSION AND DISCUSSION}

As the research results suggested there was a difference between teenager and middleaged participants of the study while using expressions and proverbs in daily conversations is concerned. Also there is a tangible variation between males and females in terms of expression usage. So, the two null hypotheses of the study have been rejected. These results may imply that females usually try an established form of language, which its comprehension by the listener is devoid of doubt and over-interpretation. On the contrary, males favour a bombastic style of narration, which requires the listener to have a powerful mental instrument of decoding and concentration. Frequent use of expressions and proverbs would be an auxiliary tool for males to impose their meaning to the listener in a very careful way. In fact, males who suppose themselves to be correct all the time, by borrowing some expressions and proverbs in the course of their speech, do not let the listener think of any other choices; acceptance.

As expressed previously, the results suggest that middle-aged speakers of our community employ more expressions than the teenagers. This may suggest that the older would have a stronger relationship with our literature and are more satisfied with their culture and identity. On the other hand, teenagers try to adopt themselves with those terms and structures, which their comprehension by the listener is guaranteed. Of course, it seems necessary to mention that the expressions and proverbs that the two previously-defined agegroups use in their daily conversations are quite different in nature. It seems that middle-aged usually use those expressions which are deeply rooted in our literature and culture while teenagers mostly use those expressions and proverbs which are suddenly entered into the 
lexicon of the society by the advent of new television series or expanded advertisements of mass media, in particular.

\section{Biography}

Mohammad Saber Khaghaninejad has a Ph. D in teaching English as a foreign language (TEFL) and at the moment is an assistant professor at Shiraz University, Iran. He has offered many general and technical courses at different Iranian universities for a decade now. His areas of interest are "language acquisition", "teaching methodology", "discourse analysis" and "critical discourse analysis".

Saharsaadat Hadigheh is a lecturer at Shiraz University of Medical Science (Paramedical faculty of Gerash), Iran. She is offering some general and technical English courses for years now. Her research interests are "teaching methodology", "linguistics" and "literary analysis".

\section{References}

[1] Petyt. K. M. (1980). The study of dialects: An introduction to dilectology. London: Andre Duetch.

[2] Labov, W. (1973). The social origins of sound change: Locating language in time and space. New York: Academic Press.

[3] Macaulay, R. K. S. (1977). Language, social class, and education. A Glassgow study. Edingburgh: Edingburgh University Press.

[4] Herbert, R. K. (1990). Sex-based differences in compliment behaviour. Explorations in the function of language. London: Edward Arnold.

[5] Lakoff, R. (1973). Language and women's place. Language and society 2, 45-80.

[6] Haas, M. R. (1964). Men's and women's speech in Koasati. Language, 20, 142-149.

[7] Wardhaugh, R. (1986). An introduction to sociolinguistics. Toronto: Basil Blackwell Inc.

[8] Gumperz, J. J. (1982). The speech community. International encyclopaedia of social sciences. London: Macmillan publications.

[9] Fasold, R. W. (1972). A linguistic and social analysis of Black English. Washington, DC: Center of applied linguistics. 